\title{
Appennino: A GIS Tool for Analyzing Wildlife Habitat Use
}

\author{
Marco Ferretti, ${ }^{1}$ Marco Foi, ${ }^{2}$ Gisella Paci, ${ }^{1}$ Walter Tosi, ${ }^{3}$ and Marco Bagliacca ${ }^{1}$ \\ ${ }^{1}$ Department of Animal Production, University of Pisa, Viale delle Piagge 2, 56100 Pisa, Italy \\ ${ }^{2}$ Department of the Earth Science, University of Milan, Via Mangiagalli 34, 20133 Milan, Italy \\ ${ }^{3}$ Geographic Information System Office, Province of Pistoia, Corso Gramsci 110, 51100 Pistoia, Italy \\ Correspondence should be addressed to Marco Ferretti, ferretti@vet.unipi.it
}

Received 1 October 2012; Revised 5 December 2012; Accepted 6 December 2012

Academic Editor: Hynek Burda

Copyright () 2012 Marco Ferretti et al. This is an open access article distributed under the Creative Commons Attribution License, which permits unrestricted use, distribution, and reproduction in any medium, provided the original work is properly cited.

The aim of the study was to test Appennino, a tool used to evaluate the habitats of animals through compositional analysis. This free tool calculates an animal's habitat use within the GIS platform for ArcGIS and saves and exports the results of the comparative land uses to other statistical software. Visual Basic for Application programming language was employed to prepare the ESRI ArcGIS 9.x utility. The tool was tested on a dataset of 546 pheasant positions obtained from a study carried out in Tuscany (Italy). The tool automatically gave the same results as the results obtained by calculating the surfaces in ESRI ArcGIS, exporting the data from the ArcGIS, then using a commercial spreadsheet and/or statistical software to calculate the animal's habitat use with a considerable reduction in time.

\section{Introduction}

Wildlife management studies identify the resources (e.g., food items or habitats) used by animals and document their availability. Resource availability is defined as the quantity accessible to the animal or populations of animals and is distinguished from abundance, which is defined as the resources in the environment [1]. Resource usage is the "quantity" taken by an animal or population of animals. Resources may be consumed, in the case of food items, or simply visited, in the case of habitats [2]. A wide variety of methods are available to study animal resource selection [3]. One such method is compositional analysis, which is often used to analyze habitat preference $[4,5]$. It studies the animal's preference both in terms of "home range" and "fix" (single positions within the home range). At present, positions and surfaces calculated in GIS programs must be exported to other free or commercial software such as spreadsheets (LibreOfficeCalc, OpenOffice, Microsoft-Excel, and so on), general statistical programs ( $\mathrm{R}$ Project for Statistical Computing, JMP, SPSS, and so on), or specific programs (Compos Analysis v.6.3-Smith ecology, BiotasEcological Software Solutions LCC).

The development of VHF- and GPS-radio collars to track animal movements [6-8] led to the need to store and transpose hundreds to thousands of positions (fixes) for each animal onto digital maps. Managing this dataset manually is complex and susceptible to errors by the use of simple spreadsheets; therefore, we produced a freely available tool, Appennino, that is completely operable within the GIS suite (ArcGIS) to calculate the animal's preferences by using compositional analysis. We decided to make the tool for "ArcGIS" since most game managers use this particular program for GIS management. However, it should be stressed that we do not have any direct financial relationship with ESRI, the producers of ArcGIS.

\section{Materials and Methods}

The tool was first coded in Visual Basic for Application (VBA) directly using the facilities provided by the ESRI ArcGIS environment $[9,10]$. The tool was based on compositional analysis $[3,11,12]$.

Appennino can be downloaded, free of charge, from http://biblio.unipi.it/content/servizio-bibliotecario/risorseweb or http://www.marcoferretti.altervista.org/index_file/ Page419.htm or http://bagliacca.altervista.org/GIStool.html. The tool needs at least four "shapes": the land use polygon layer, the home range polygon shape of every individual animal, the land use circular random plots, and the fix layer 


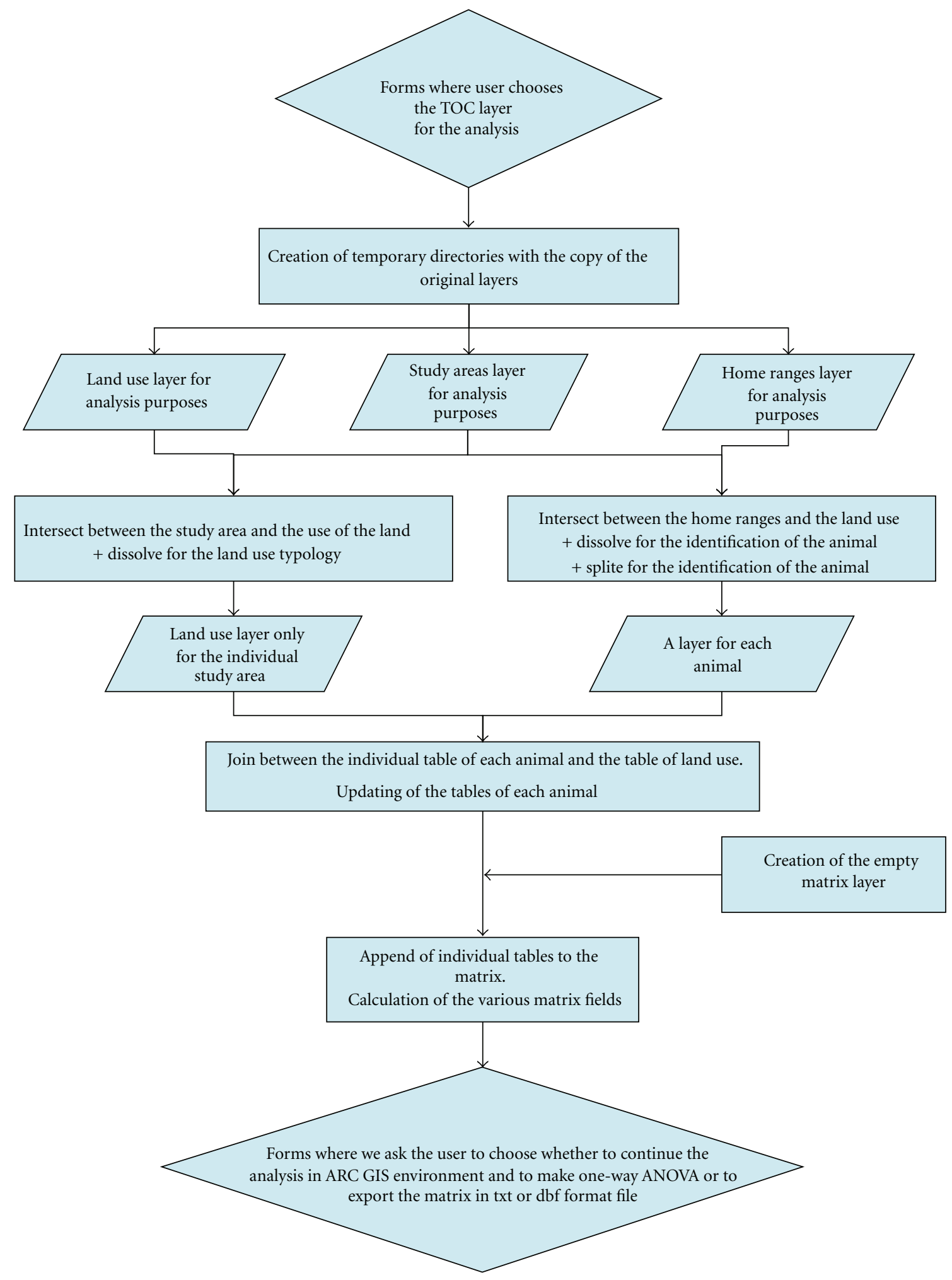

Figure 1: Flow chart of the first step of the tool.

of the animals. The tool works both on home range and fix analyses.

The tool works as follows. It assumes there are $D$ types of resource units available, and that the individual animal's proportional resource usage is described by the composition $o_{u 1}, o_{u 2}, \ldots, o_{u D}$, where $o_{u i}$ is the estimated proportion of the $i$ type resource used by the individual. The proportions sum to one. Similarly, the analysis sets the available proportions for the same animals as $\pi_{a 1}, \pi_{a 2}, \ldots, \pi_{a D}$. The analysis cannot be applied when resources units are described by 


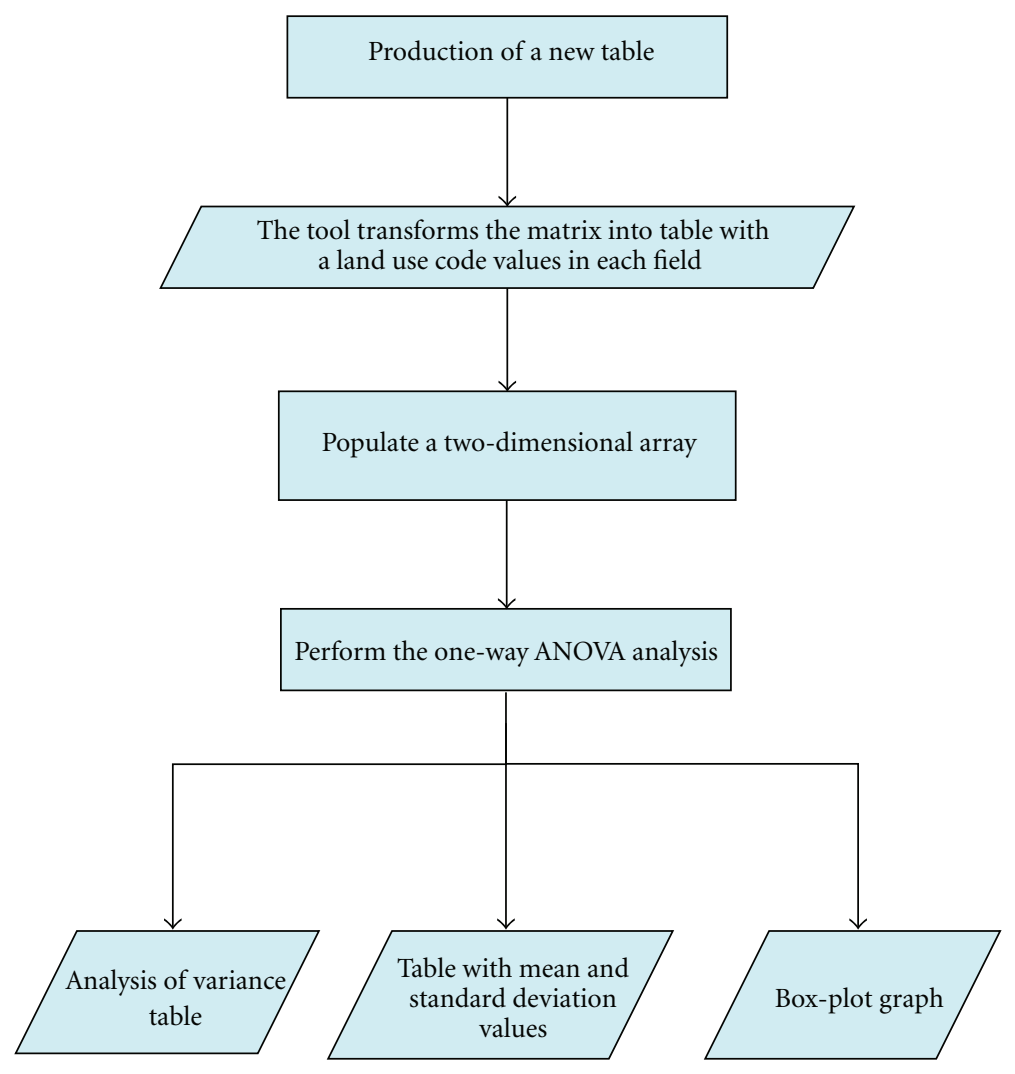

FIgURE 2: Flow chart of the second step of the tool.

continuous variables, unless they are expressed as discrete classes. The log-ratio transformation $y_{i}=\log _{e}\left(o_{u i} / o_{u j}\right)$ is calculated for any component $o_{j}$. The differences $i=$ $\log _{e}\left(o_{u i} / o_{u j}\right)-\log _{e}\left(\pi_{a i} / \pi_{a j}\right)$ are then calculated for the $i$ th animal to represent the difference between the relative use and availability of resources $i$ and $j$. Problems related to the sampling level [13-15] are avoided, since the animal is used as the unit of observation, so that data independence and multivariate normality are ensured. With no selection, the mean value of $d_{i}$ is expected to be zero for all $i$. Generally speaking, in software applications when there are zero values, land use cannot be calculated and an error message is generated. Our tool avoids the problem by replacing zero values with a value corresponding to $1 \%$ of the smallest value observed, although the substitution of zero values with arbitrary constants has led to some criticism of the method [12]. The tool works through a two-step process. In the first step, the definition of the analysis matrix is derived from primary data (this data array can be exported in ".txt" or ".dbf" file format to be used in other statistical software). In the second step, an ANOVA test can be run directly on the newly created matrix, without leaving the ArcGIS environment.

Figures 1 and 2 show how the program works.

\section{Results and Discussion}

Figures 4 and 5 show the final output of the tool when it was applied to data from a study carried out between 2008 and 2009 on a group of pheasants (Phasianus colchicus) released in a protected area (PA) near Florence (Tuscany, Italy, Figure 3) $[6,16]$ at the end of the two steps.

The Appennino tool is completely operable within the ArcGIS suite to evaluate animal preferences by compositional analysis. This enables it to be maintained within the GIS software and avoids having to export the database to any external statistical software, while producing the same results as other statistical software.

\section{Conclusions}

We have presented Appennino as a tool that automatically gives the complete matrix of the compositional analysis, which can then be exported in other statistical software packages for further statistical analysis. Our tool thus prevents calculation errors with high quantities of data and is also easy to use. In addition, Appennino performs basic statistics of the data set, is free of charge, and can be downloaded with the VBA source code for further improvements.

\section{Acknowledgments}

The authors would like to thank Daniel S. Soper, PhD. Assistant Professor Department of Information Systems and Decision Sciences Mihaylo College of Business and Economics California State University Fullerton and Provincia di Pistoia and Ambito Territoriale di Caccia Firenze 5 for 


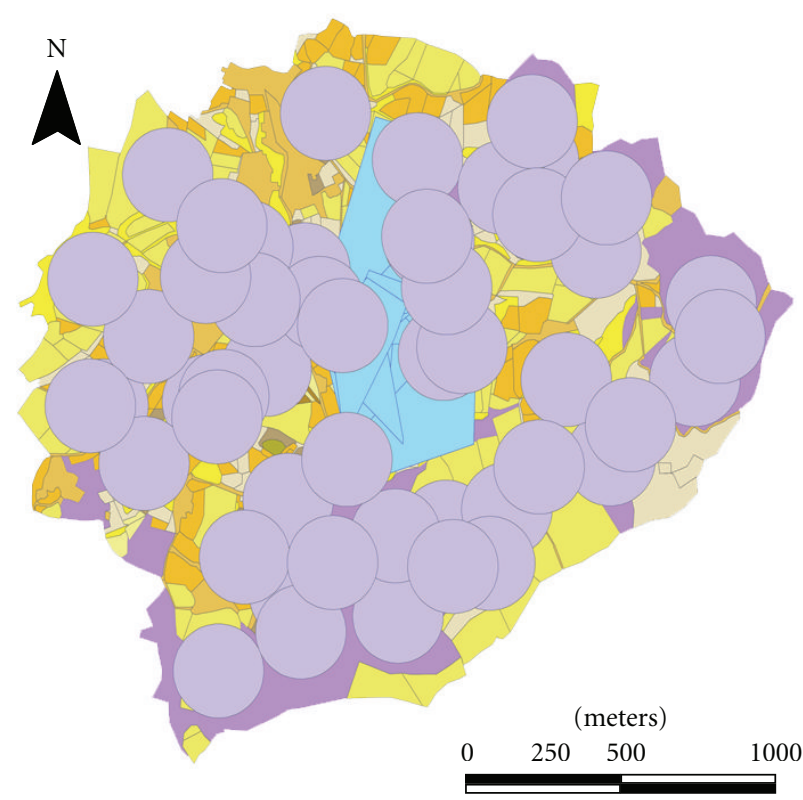

\begin{tabular}{l}
\hline Availability plots \\
\hline$\square$ Home ranges \\
Land use \\
Mediterranean wood \\
Shrub land \\
Fallow land \\
Vineyards
\end{tabular}

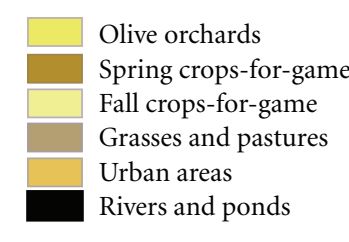

FIGURE 3: Land use polygon layer with the home range polygon shape of each individual animal and the land use circular plots generated with the Hawth tool (http://www.spatialecology.com/htools/), from the ArcGIS table of contents. Note: the land use layer, performed for clarity, is not required by the tool. With this set of data, 50 random circular plots of the average home range size of the birds in the case study $(110 \mathrm{~m})$ were chosen across the study area.

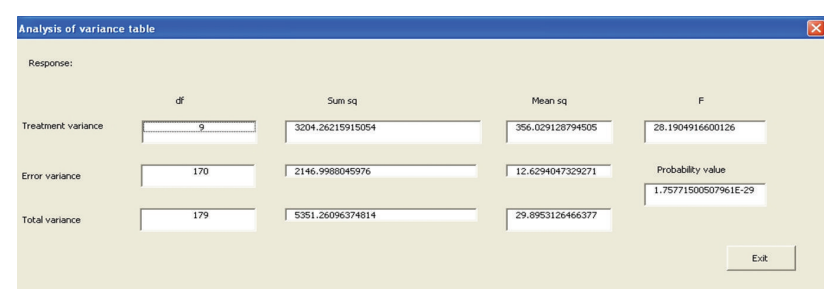

Figure 4: Analysis of variance table.

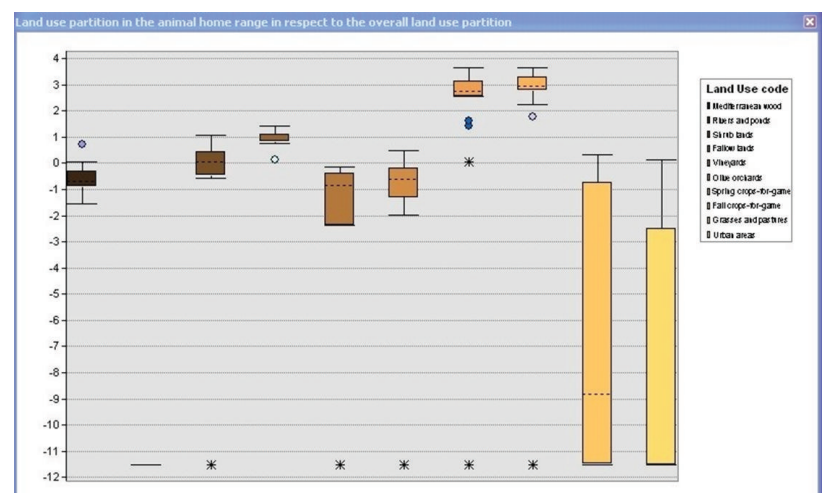

Figure 5: Box-plot graph of the land uses. Note: with this data set, the land uses which give maximum values of occurrence are "Spring crops-for-game" and "Fall crops-for-game." The land uses which give the least uses are the "Rivers and ponds" and "Urban areas" $(P<0.05)$. 
their cooperation. The authors of the paper do not have any financial association with ESRI, the producers of the program mentioned in the paper.

\section{References}

[1] J. R. Alldredge, D. L. Thomas, and L. L. Mcdonald, "Survey and comparison of methods for study of resource selection," Journal of Agricultural, Biological, and Environmental Statistics, vol. 3, no. 3, pp. 237-253, 1998.

[2] B. F. J. Manly, "Comments on design and analysis of multiplechoice feeding-preference experiments," Oecologia, vol. 93, no. 1, pp. 149-152, 1993.

[3] B. F. J. Manly, L. L. McDonald, D. L. Thomas, T. L. McDonald, and W. P. Erickson, Resource Selection By Animals: Statistical Design and Analysis For Field Studies, Kluwer Academic Publishers, Boston, Mass, USA, 2nd edition, 2002.

[4] T. M. Fearer and D. F. Stauffer, "Relationship of ruffed grouse Bonasa umbellus to landscape characteristics in southwest Virginia, USA," Wildlife Biology, vol. 10, no. 2, pp. 81-89, 2004.

[5] M. Ferretti, G. Paci, S. Porrini, L. Galardi, and M. Bagliacca, "Habitat use and home range traits of resident and relocated hares [Lepus europaeus, Pallas)," Italian Journal of Animal Science, vol. 9, no. 3, pp. 278-284, 2010.

[6] M. Ferretti, F. Falcini, G. Paci, and M. Bagliacca, "Captive rearing technologies and survival of pheasants (Phasianus colchicus L.)," Italian Journal of Animal Science, vol. 11, no. e2, pp. 160-164, 2012.

[7] B. Zweifel-Schielly and W. Suter, "Performance of GPS telemetry collars for red deer Cervus elaphus in rugged Alpine terrain under controlled and free-living conditions," Wildlife Biology, vol. 13, no. 3, pp. 299-312, 2007.

[8] M. Pellerin, S. Said, and J. M. Gaillard, "Roe deer Capreolus capreolus home-range sizes estimated from VHF and GPS data," Wildlife Biology, vol. 14, no. 1, pp. 101-110, 2008.

[9] R. Burke, Getting To Know Arcobjects: Programming ArcGIS With VBA, ESRI, 2003.

[10] K. T. Chang, Programming ArcObjects With VBA: A taskOriented Approach, CRC, 2007.

[11] N. J. Aebischer, P. A. Robertson, and R. E. Kenward, "Composition analysis of habitat use from animal radio-tracking data," Ecology, vol. 74, no. 5, pp. 1313-1325, 1993.

[12] G. W. Pendleton, K. Titus, E. Degayner, C. J. Flatten, and R. E. Lowell, "Compositional analysis and GIS for study of habitat selection by goshawks in Southeast Alaska," Journal of Agricultural, Biological, \& Environmental Statistics, vol. 3, no. 3, pp. 280-295, 1998.

[13] S. H. Hurlbert, "Pseudoreplication and the design of ecological field experiments," Ecological Monographs, vol. 54, pp. 187211, 1984.

[14] R. E. Kenward, "Quality versus quantity: programmed collection and analysis of radio-tracking data," in Wildlife Telemetry: Remote Monitoring and Tracking of Animals, I. G. Priede and S. M. Swift, Eds., pp. 231-246, Ellis Horwood, Chichester, UK, 1992.

[15] R. Kenward, Wildlife Radiotagging. Equipment, Field Techniques and Data Analysis, Academic Press, London, UK, 1993.

[16] M. Ferretti, F. Falcini, G. Paci, and M. Bagliacca, "Radiotracking of Pheasants (Phasianus colchicus L.) to test captive rearing technologies," in Telemetry, O. Krejcar, Ed., vol. 5, pp. 403422, Animal Telemetry Tech, 2011. 

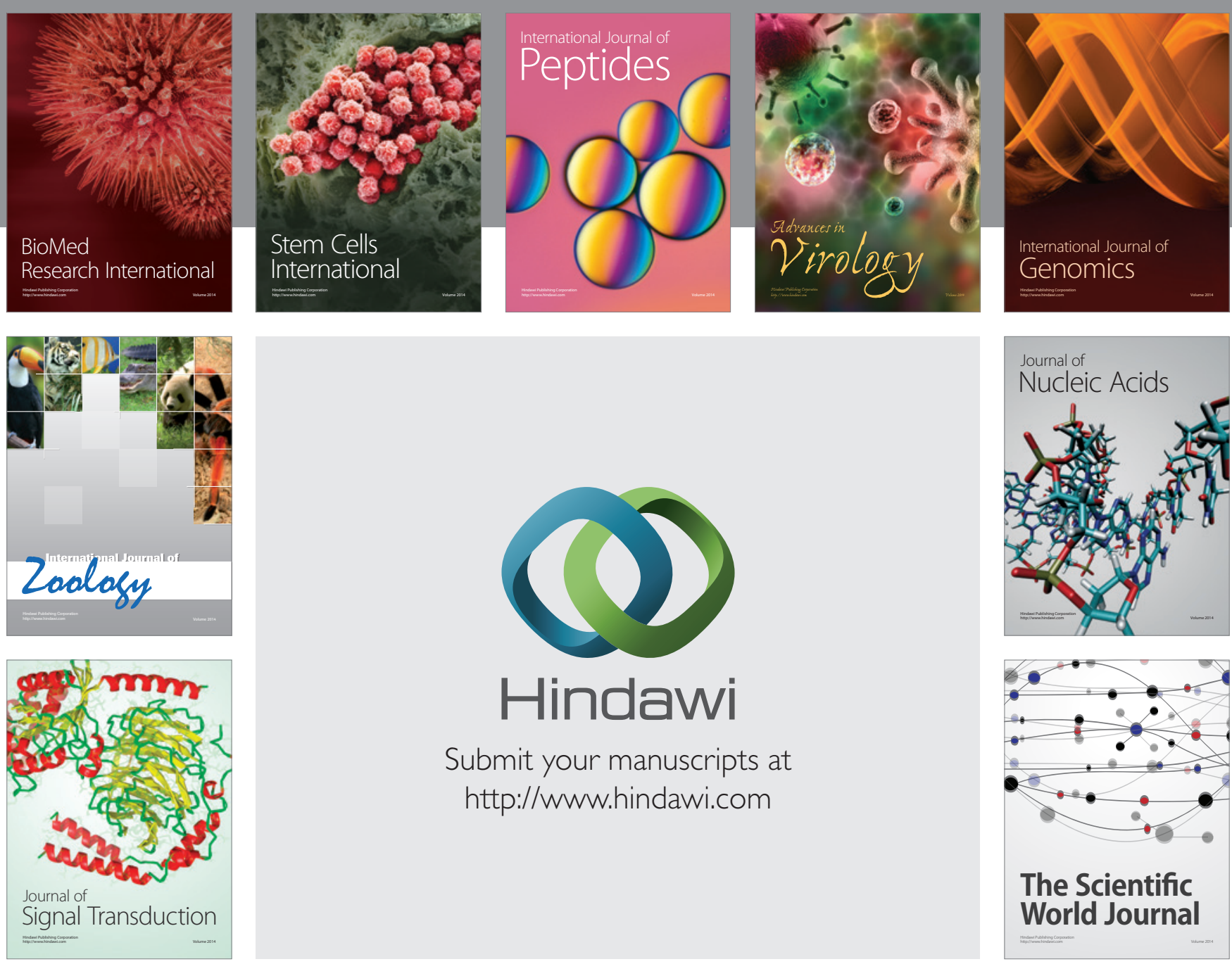

Submit your manuscripts at

http://www.hindawi.com
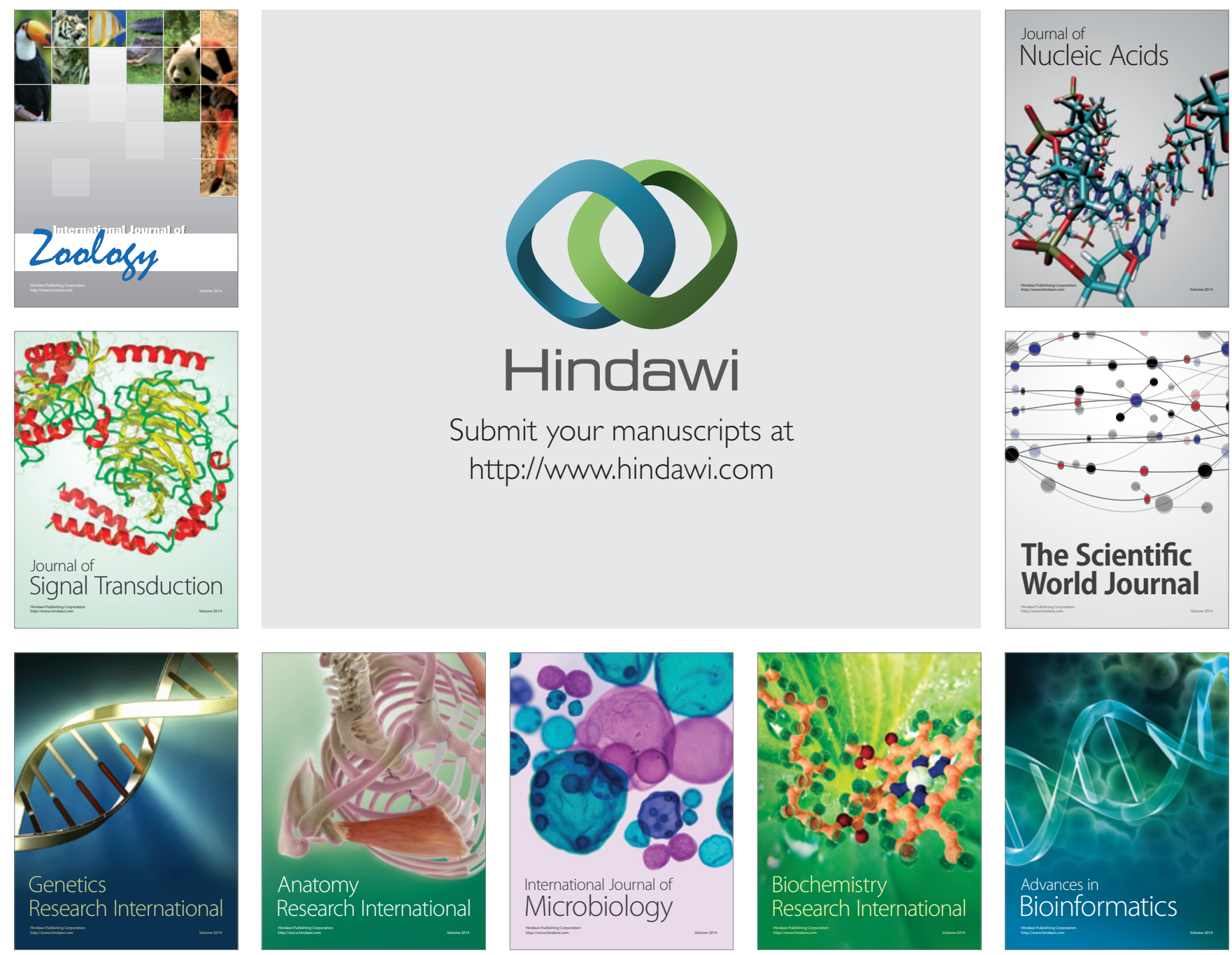

The Scientific World Journal
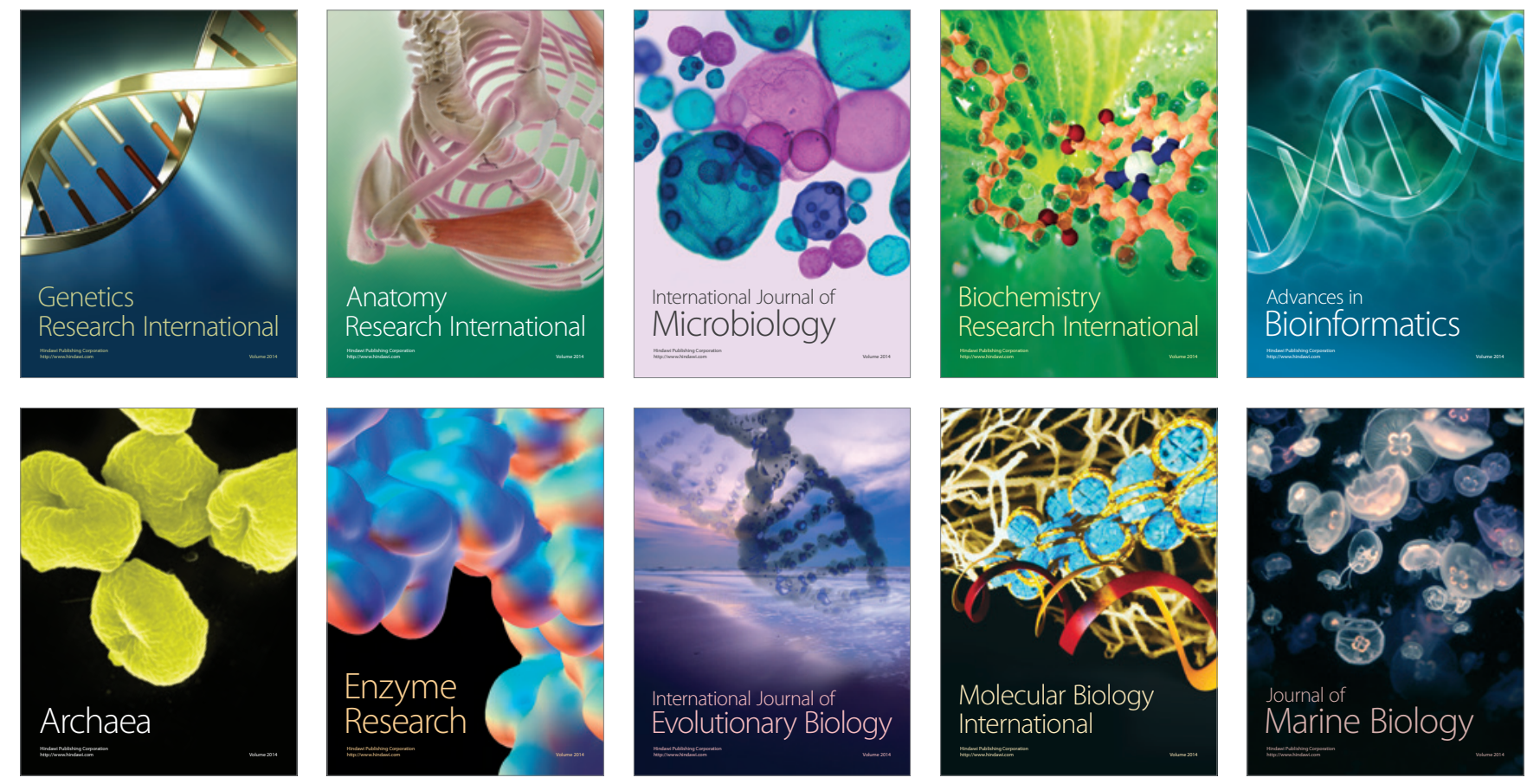